\title{
ESTUDO COMPARATIVO ENTRE DIVERSOS TIPOS DE TRATAMENTO PARA PERITONITE FECAL EM RATO
}

\author{
COMPARISON BETWEEN SEVERAL TREATMENTS FOR FECAL \\ PERITONITIS IN RAT
}

\author{
Bruno Gustavo Muzzi Carvalho e Carneiro ${ }^{1}$ \\ Andy Petroianu, TCBC-MG ${ }^{2}$ \\ Fernando Henrique Oliveira Carmo Rodrigues ${ }^{3}$ \\ Renata Figueiredo Rocha $^{4}$
}

\begin{abstract}
RESUMO: Objetivo: A peritonite é responsável por aproximadamente 50\% das mortes por sepse e, apesar de avanços nos métodos usados para o seu diagnóstico e tratamento, cerca de um terço dos pacientes ainda morre de peritonite secundária grave. O objetivo do presente trabalho foi comparar a eficácia de diversos tipos de tratamento para a peritonite fecal grave e estabelecida. Métodos: Foram usadas 40 ratas adultas, submetidas à peritonite fecal com injeção intraperitoneal de uma suspensão de fezes de ratos. Os animais foram divididos em oito grupos $(\mathrm{n}=5)$ : Grupo 1, controle; Grupo 2, limpeza mecânica intraperitoneal com gaze; Grupo 3, lavagem com solução salina a $0,9 \%$, à temperatura ambiente; Grupo 4, lavagem com solução salina a $0,9 \%$, a 37, $8^{\circ} \mathrm{C}$; Grupo 5 , lavagem com povidona-iodo a $0,5 \%$; Grupo 6 , lavagem com clorexidina a $0,05 \%$; Grupo 7, injeção intramuscular de gentamicina e clindamicina; Grupo 8, introdução intraperitoneal de açúcar. Resultados: Os grupos 5 e 8 foram os que apresentaram a mortalidade mais rápida (menos de 24 horas). Após 72 horas, permaneceu viva uma rata em cada um dos grupos 2, 3, 4 e 6. Nos grupos 1, 5, 7 e 8 não houve sobrevida. Apesar de todos os animais do Grupo 7 morrerem, o óbito ocorreu em um período mais longo (72 horas) do que o dos demais grupos. Conclusão: Somente ocorreu sobrevida nos grupos submetidos à limpeza peritoneal menos agressiva. Além disso, um procedimento terapêutico único de limpeza ou antibiótico sistêmico por um dia não é suficiente para prevenir a morte em ratos com peritonite fecal grave e estabelecida.
\end{abstract}

Descritores: Peritonite fecal; Sepse; Tratamento; Lavagem peritoneal, Rato.

\section{INTRODUÇÃO}

Peritonite é a resposta inflamatória da serosa peritoneal a uma agressão. Pode ser primária (sem lesão de vísceras, como em pacientes com cirrose ou nefropatia), secundária (após lesões perfurantes, inflamatórias, infecciosas ou isquêmicas intra-abdominais) e terciária (por distúrbio na resposta imune) ${ }^{1-4}$. Atualmente, a peritonite é responsável por aproximadamente 50\% das mortes por sepse e, apesar da melhoria nos métodos diagnósticos, potentes antibióticos, modernas unidades de tratamento intensivo e terapêutica cirúrgica criteriosa, cerca de um terço dos pacientes ainda morre de peritonite secundária grave $^{1,3-13}$.

Inicialmente, o peritônio permite que toxinas e outros materiais presentes no líquido peritoneal sejam absorvidos e provoquem distúrbios sistêmicos. Concomitantemente, a serosa peritoneal responde às agressões com hiperemia seguida de transudação e exsudação. Ocorre também um elevado aporte de fibroblastos que produzem

1. Acadêmico da Faculdade de Medicina da UFMG, Bolsista de Iniciação Científica da FAPEMIG.

2. Professor Titular do Departamento de Cirurgia da Faculdade de Medicina, UFMG, Livre-docente de Técnica Operatória e Cirurgia Experimental da Escola Paulista de Medicina, UNIFESP, Livre-docente de Gastroenterologia Cirúrgica da Faculdade de Medicina de Ribeirão Preto, USP, Doutor em Fisiologia e Farmacologia pelo Instituto de Ciências Biológicas, UFMG, Pesquisador IA do CNPq.

3. Acadêmico da Faculdade de Medicina da UFMG.

4. Acadêmica da Faculdade de Medicina da UFMG.

Recebido em 03/03/2001

Aceito para publicação em 22/11/2001

Trabalho realizado no Departamento de Cirurgia da Faculdade de Medicina da UFMG, sob o patrocínio do CNPq e da FAPEMIG. 
a fibrina, responsável pela formação de aderências intraabdominais. O extravasamento de água, eletrólitos e proteínas para a cavidade peritoneal repercute com hipovolemia, choque e hipoalbuminemia. $\mathrm{O}$ intestino reage com hipermotilidade transitória inicial seguida por íleo adinâmico quase total e distensão enterocólica ${ }^{3,5}$.

A sepse associada à peritonite ocorre em graus variáveis, dependendo da agressividade dos patógenos, da carga bacteriana, da extensão e duração da contaminação, da interação sinérgica, bem como da adequação da terapia inicial. Caso o tratamento seja incapaz de proporcionar o imediato controle da infecção peritoneal, poderá ocorrer endotoxemia e choque séptico ${ }^{1,3,4}$. Na peritonite secundária à contaminação por conteúdo gastrintestinal, encontra-se uma flora polimicrobiana que atua de forma sinergística, composta por bacilos coliformes aeróbios, sobretudo a Escherichia coli, bacteróides anaeróbios, estreptococos, enterococos e clostrídios, entre outros ${ }^{1,3,4,6}$ Estudos experimentais mostraram que a infecção é bifásica e, após a fase inicial, a diversidade bacteriana é reduzida a poucos organismos, com um predomínio de Escherichia coli, na fase aguda, e de anaeróbios, principalmente Bacteroides fragilis, na fase tardia. Esses achados são semelhantes aos encontrados em humanos ${ }^{4,14,15}$.

Pesquisas clínicas com diferentes abordagens terapêuticas da sepse intra-abdominal são de difícil comparação, devido à presença de múltiplas variáveis, tais como a natureza da doença de base, a quantidade e patogenicidade da microflora agressora, o tempo passado até o início da terapia e o tipo de tratamento. Experimentalmente, existem três modelos principais de peritonite séptica descritos com mais freqüência na literatura: injeção de bactérias na cavidade peritoneal, injeção de fezes e abertura de um segmento intestinal ${ }^{7-9,14-21}$.

Os princípios do tratamento cirúrgico da peritonite, propostos por Kirschner, em 1926, permanecem como base do tratamento dessa afecção: a cirurgia deve ser realizada precocemente; a incisão deve ser feita sobre o foco da infecção, mas caso haja alguma dúvida deve-se optar por uma laparotomia ampla; remover a fonte da infecção, os líquidos e demais contaminantes da cavidade peritoneal. Com essa conduta, a mortalidade global da peritonite foi reduzida de $87 \%$ para $30 \%$.

A história do tratamento cirúrgico da peritonite revela o uso de vários tipos de soluções para lavar a cavidade abdominal (salina, pepsina ácida, ácido carbólico, cloreto de mercúrio, ácido salicílico, ácido etacridínico, água, óleo de cânfora, óleo de cânfora com éter, hipoclorito de sódio, glicose hipertônica, álcool, éter, noxitiolina, povidona-iodo, clorexidina, peróxido de hidrogênio, antibióticos etc. $)^{6,13}$.

A introdução da lavagem peritoneal com solução salina é atribuída a Torek que, em 1911, conseguiu excelentes resultados com esse método ${ }^{13}$. A lavagem copiosa remove substâncias sépticas, sangue, coágulos de fibrina, dilui as bactérias residuais e colabora para a expansão do volume intravascular. Em contrapartida, essa conduta também dilui opsoninas, remove macrófagos, linfócitos e poli- morfonucleares, responsáveis pela fagocitose das bactérias, prejudicando os mecanismos de defesa locais, além de contaminar áreas limpas, sendo contra-indicada nas formas localizadas de peritonite ${ }^{1,3,8,10,13}$. O próprio trauma induzido pela lavagem pode ser responsável pelo agravamento da peritonite. Existe ainda a possibilidade de a inflamação induzida pela lavagem facilitar a translocação bacteriana para fora do abdome. Além disso, a lavagem com cristalóides não tem sido associada à redução da mortalidade $8,13,18$.

Por outro lado, Maingot ${ }^{12,20}$ acreditava que a irrigação da cavidade peritoneal não se justificava, mesmo na presença de contaminação fecal grosseira. A limpeza mecânica exclusiva, com aspiração dos líquidos e posterior remoção dos contaminantes por meio de compressas, não prejudicaria os mecanismos de defesa orgânicas e não disseminaria o conteúdo séptico a toda cavidade abdominal. No entanto, diversos autores consideram que esse tipo de procedimento não remove o inóculo bacteriano de forma satisfatória ${ }^{3,6,8,13}$.

A lavagem intraperitoneal com anti-sépticos fundamenta-se na atividade específica bactericida de largo espectro dessas substâncias. Contudo, diversos trabalhos condenam esse método por seus efeitos tóxico e irritativo, que agravam a peritonite e predispõem à formação de aderências ${ }^{1,3,5,7,9,13,22}$. Já aqueles que os defendem consideram que os maus resultados decorrem de seu uso inadequado, em concentrações exageradas e por tempo prolongado ${ }^{7,9,22-24}$. Mathews ${ }^{23}$ conseguiu sucesso no tratamento da peritonite em ratos, com o uso da solução de povidona-iodo a $0,5 \%$. Sua presumível ação depende da liberação do radical iodo, após cinco minutos de contato da droga com o tecido. Após esse tempo, deve-se enxaguar o local a fim de retirar o excesso do produto ${ }^{25}$.

A clorexidina é eficaz contra microrganismos grampositivos e gram-negativos, além de possuir baixa toxicidade celular, porém tem sua eficácia rapidamente reduzida em presença de matérias orgânicas, como pus ou sangue $^{24}$. Experimentalmente, a clorexidina diluída a $0,05 \%$ diminuiu a concentração de bactérias no peritônio e a mortalidade de animais ${ }^{1,3,9,16}$. Seu uso em humanos limita-se a cirurgias orais e a poucos estudos em peritoni$\mathrm{te}^{9,13}$.

O uso de antibióticos por lavagem peritoneal não mostrou vantagem em relação à sobrevida ou presença de infecção sobre a solução salina a $0,9 \%$ 1,12,18,26. Já com relação à antibioticoterapia sistêmica, o seu valor é inegável e diversos antibióticos e esquemas terapêuticos são propostos $^{3,4,5,11,27,28,29}$.

O açúcar é muito utilizado no tratamento local de feridas infectadas, com excelentes resultados. $\mathrm{O}$ seu efeito bactericida se dá por ação osmótica ${ }^{30}$. Por outro lado, é sabido que a adição de uma substância hipertônica no interior da cavidade peritoneal pode gerar hipotensão e até choque hipovolêmico devido ao desvio de água do espaço

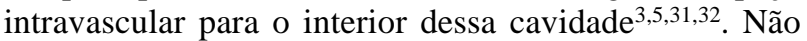
há, no entanto, relatos na literatura a respeito do uso de açúcar no tratamento da peritonite séptica. 
O objetivo do presente trabalho foi comparar a eficácia de diversos tipos de tratamento para a peritonite séptica grave e estabelecida.

\section{MÉTODOS}

O presente trabalho foi realizado de acordo com as recomendações das Declarações de Helsinque e as Normas Internacionais de Proteção aos Animais e aprovado pela Comissão de Ética da Universidade Federal de Mingas Gerais, UFMG ${ }^{33,34}$.

Foram utilizadas 40 ratas Wistar adultas, pesando entre 200 e 330 gramas, procedentes do biotério do Instituto de Ciências Biológicas da UFMG e acondicionadas no biotério da Faculdade de Medicina da UFMG.

Em todos os animais induziu-se a peritonite fecal com injeção intraperitoneal de uma suspensão de fezes (recém-defecadas) de ratos, a $10 \%$, na quantidade de $5 \mathrm{ml} /$ $\mathrm{kg}$ de peso corpóreo. Essa suspensão foi preparada colocando-se $2 \mathrm{~g}$ de fezes em um frasco e adicionando-se uma quantidade de solução salina suficiente para completar 20 mililitros de solução. Posteriormente, essa mistura foi homogeneizada e filtrada através de gaze para remover as partículas fecais maiores.

As operações foram sob anestesia com éter etílico. As intervenções terapêuticas foram realizadas através de laparotomia mediana e a cavidade abdominal foi fechada em dois planos com sutura contínua, utilizando fio de poligalactina 5-0.

Foram realizados testes de Gram, cultura e antibiograma da suspensão de fezes no início do experimento.

A suspensão de fezes foi injetada no peritônio. Após oito horas, o tratamento proposto foi realizado. Os ratos foram divididos aleatoriamente em oito grupos $(n=5)$, de acordo com o seguinte protocolo:

- Grupo 1 - controle: nenhum tipo de tratamento foi realizado.

- Grupo 2 - limpeza mecânica: o abdome foi limpo com gazes umedecidas em solução salina para remover todo o conteúdo líquido acumulado na cavidade abdominal.

- Grupo 3 - lavagem intraperitoneal com solução salina a $0,9 \%$, à temperatura ambiente: a cavidade abdominal foi profusamente lavada com uma seringa. Em seguida, o líquido foi completamente aspirado, por meio de seringa.

- Grupo 4 - lavagem intraperitoneal com solução salina a $0,9 \%$, aquecida a $37,8^{\circ} \mathrm{C}$ : a cavidade abdominal foi profusamente lavada com uma seringa. Em seguida, o líquido foi aspirado.

- Grupo 5 - lavagem com povidona-iodo a 0,5\%: a cavidade abdominal foi lavada com $4 \mathrm{ml}$ da solução de povidona-iodo a $0,5 \%$ instilada com uma seringa. Após cinco minutos, o líquido foi aspirado e o peritônio enxugado com gaze.

- Grupo 6 - lavagem com clorexidina a $0,05 \%$ : a cavidade abdominal foi profusamente lavada com clorexidina a $0,05 \%$ instilada com uma seringa. Após cinco minutos, o líquido foi aspirado.
- Grupo 7 - antibióticos sistêmicos: 4mg/kg de gentamicina e $40 \mathrm{mg} / \mathrm{kg}$ de clindamicina foram injetados, em dose única, por via muscular. Estes animais não foram submetidos à laparotomia.

- Grupo 8 - açúcar: foi adicionado açúcar cristal, na quantidade de $1 \mathrm{~g} / 100 \mathrm{~g}$ de peso corpóreo, à cavidade peritoneal.

Os ratos foram observados até sua morte e submetidos à necropsia. Os animais que sobreviveram foram mortos após 30 dias com dose excessiva de éter alcoólico e submetidos à necropsia.

Para a análise estatística utilizou-se o teste do Quiquadrado; valores correspondentes a $p<0,05$ foram considerados significativos.

\section{RESULTADOS}

A análise pelo método de Gram das fezes revelou a presença de múltiplos bastonetes Gram-negativos, bastonetes Gram-positivos e alguns cocos Gram-positivos isolados e aos pares. Na cultura, houve o crescimento de Escherichia coli e Pseudomonas aeruginosa. O antibiograma mostrou sensibilidade dos microrganismos a todos os antibióticos testados (sulfametoxazol-trimetoprim, ampicilina, amoxicilina-clavulanato, cefalotina, cefazolina, cefoxitina, cefuroxima, ceftriaxona, ceftazidima, cefepima, ciprofloxacin e gentamicina), com exceção da Pseudomonas aeruginosa que foi resistente ao sulfametoxazol-trimetoprim.

A sobrevida dos animais pertencentes aos oito grupos está na Tabela 1 .

À laparotomia, para os procedimentos terapêuticos propostos nos diversos grupos, verificou-se hiperemia generalizada, líquido peritoneal turvo, fibrina e algumas aderências intestinais.

No primeiro dia, os animais do Grupo 7 apresentaram a menor mortalidade em relação aos demais grupos, porém sem diferença significativa. A morte dos animais foi mais rápida (todos os ratos em menos de 24 horas) nos grupos 5 e 8. Ela ocorreu em um tempo menor, inclusive ao registrado no grupo controle.

A necropsia de todos os animais revelou peritonite difusa com odor fétido, intensa hiperemia generalizada, líquido peritoneal turvo, fibrina, abscessos em diversas localizações, aderências intestinais mais intensas e dilatação enterocolônica. Em alguns ratos, verificou-se necrose em segmentos hepáticos. No tórax, encontrou-se líquido pleural abundante, bilateral, porém límpido.

Após 72 horas, não houve mais óbitos e quatro animais dos grupos $(\mathrm{n}=1)$ 2, 3, 4 e 6 sobreviveram por 30 dias. À necropsia, o peritônio não estava inflamado, não havia líquido intracavitário, porém foram evidenciadas múltiplas aderências viscerais. Na cavidade torácica não foi encontrado líquido. 
Tabela 1

Mortalidade de cada grupo de ratos em relação ao tipo de tratamento e tempo

\begin{tabular}{|c|c|c|c|c|}
\hline \multirow[b]{2}{*}{ Grupos $(n=5)$} & \multicolumn{3}{|c|}{ Tempo (horas) } & \multirow[b]{2}{*}{ Sobreviveram } \\
\hline & 24 & 48 & 72 & \\
\hline 1) Controle & 5 & - & - & - \\
\hline 2) Limpeza mecânica & 3 & 1 & - & 1 \\
\hline 3) Solução salina à temperatura ambiente & 3 & 1 & - & 1 \\
\hline 4) Solução salina a $37,8^{\circ} \mathrm{C}$ & 4 & - & - & 1 \\
\hline 5) Povidona - Iodo & 5 & - & - & - \\
\hline 6) Clorexidina & 4 & - & - & 1 \\
\hline 7) Antibiótico* & 2 & 2 & 1 & - \\
\hline 8) Glicose & 5 & - & - & - \\
\hline
\end{tabular}

* Os antibióticos utilizados foram: Gentamicina (4mg/kg) e Clindamicina (40mg/kg).

\section{DISCUSSÃO}

O presente trabalho teve como objetivo avaliar procedimentos terapêuticos em peritonite estabelecida e grave. Para isso, em projetos-pilotos, foram estudadas diferentes quantidades de fezes e vários tempos para proceder o tratamento. Quando a quantidade de fezes foi menor, parte dos ratos do grupo controle não morria, fato que dificultaria a interpretação dos resultados terapêuticos.

Optou-se por não repetir os procedimentos terapêuticos nos dias subseqüentes, para manter o objetivo do trabalho de avaliar condutas sobre a contaminação fecal e não sobre as complicações peritoneais advindas posteriormente. Ao final do experimento, não houve diferença na mortalidade em relação ao grupo controle. Portanto, nas condições do presente experimento, nenhum dos tratamentos estudados, na forma em que foi instituído, mostrou-se eficaz.

Um fator que pode ter contribuído para a elevada mortalidade é o tempo do procedimento terapêutico após a indução da peritonite fecal. A literatura cita o tratamento sendo realizado desde cinco minutos até seis horas após a indução da peritonite ${ }^{7-9,18,21}$. Nós optamos por realizar os tratamentos mais tardiamente (oito horas) a fim de ter maior segurança de que a peritonite já estaria instalada. No estudo-piloto, períodos menores acompanharam-se de elevada sobrevida com a maioria dos tratamentos, sugerindo que a limpeza das fezes ocorreu antes de a peritonite ter se estabelecido. Ao comparar os resultados do presente trabalho com os da literatura, poder-se-ia pressupor que uma vez estabelecida a peritonite, o tratamento apenas local e realizado uma única vez é insuficiente.

Devem-se ressaltar os melhores resultados parciais do grupo tratado apenas com antibióticos sistê- micos, sem uma ação direta sobre a contaminação abdominal. Com base nesses achados, reforça-se a hipótese de a morte ser, pelo menos parcialmente, devida à sepse, complicação que não pode ser combatida apenas com a limpeza peritoneal, independente do método utilizado.

O líquido abundante encontrado à necropsia no espaço pleural pode ser interpretado como uma reação dessa serosa que habitualmente ocorre nas peritonites graves.

Observou-se que a morte dos animais somente ocorreu nos primeiros três dias do experimento. Isso pode ser devido à repercussão sistêmica aguda da peritonite. Nos animais em que o sistema imunitário controlou a sepse, os ratos sobreviveram. A cura provavelmente não decorreu do tratamento, mas das próprias defesas orgânicas do animal à sepse, após a limpeza eficaz do peritônio. Mesmo que a pequena sobrevida não seja suficiente para uma avaliação estatisticamente substanciada, é interessante observar que somente sobreviveram animais dos grupos em que as fezes foram removidas e de uma maneira menos agressiva. É possível que o iodo do Grupo 5 e o meio hipertônico do Grupo 8 tenham sido eles próprios responsáveis pela morte mais precoce de todos os animais. Já no Grupo 7 , por ter permanecido com as fezes intraperitonealmente, a sepse não pôde ser combatida por dose única do antibiótico.

De acordo com os resultados do presente trabalho, concluímos que um procedimento terapêutico único de limpeza ou antibiótico sistêmico por um dia não é eficaz em prevenir a morte em ratos com peritonite fecal grave e estabelecida. Cabe prosseguir na mesma linha de pesquisa no sentido de verificar a eficácia terapêutica desses procedimentos em modelos de repetição terapêutica e combinados. 


\begin{abstract}
Background: Despite improvements in diagnosis and treatment of severe peritonitis, one third of patients still die. The purpose of the present study was to compare the efficacy of several treatments on severe and established fecal peritonitis. Methods: Forty adult Wistar rats, were submitted to intraperitoneal injection of a rat feces solution. Animals were divided into 8 groups $(n=5)$ : Group 1, control; Group 2, intraperitoneal mechanical cleaning with gauze; Group 3, cleaning with $0.9 \%$ saline solution, at $23^{\circ} \mathrm{C}$; Group 4, cleaning with $0.9 \%$ saline solution, at $37.8^{\circ} \mathrm{C}$; Group 5, cleaning with $0.5 \%$ povidone-iodine; Group 6, cleaning with $0.05 \%$ chlorhexidine; Group 7, intramuscular injection of gentamicin and clindamycin; and Group 8, administration of intraperitoneal sugar. Results: The animals of groups 5 and 8 had precocious death. After 72 hours, one rat of each group 2, 3, 4 and 6 survived. No rat of groups 1, 5, 7, 8 survived. However, the animals of Group 7 remained alive for a longer period (72 hours). Conclusions: Survival occurred only in groups submitted to less aggressive peritoneal cleaning. Besides, only one peritoneal cleaning or a single dose of antibiotic is not sufficient to prevent death due to severe and established fecal peritonitis.
\end{abstract}

Key Words: Fecal peritonitis; Sepsis; Treatment; Peritoneal cleaning; Rat.

\title{
REFERÊNCIAS
}

1. Boey, JH. “Cavidade peritoneal”. In: Way, LW (ed). Cirurgia - Diagnóstico e Tratamento. 9a edição. Rio de Janeiro. Guanabara Koogan, 1993, pp.321-333.

2. Diethelm AG, Stanley RJ. "O abdômen agudo". In Sabiston DC (ed). Tratado de Cirurgia. 14 a edição. vol 1. Rio de Janeiro. Guanabara Koogan, 1993, pp.696714.

3. Walker AP, Condon RE. 'Peritonite e abscessos intra-abdominais". In: Schwartz SI (ed). Princípios de Cirurgia. $5^{\text {a }}$ edição. Rio de Janeiro. Guanabara Koogan, 1991, pp. 1216-1242.

4. Wittmann DH, Schein M, Condon RE. Management of secondary peritonitis. Ann Surg, 1996; 224: 10-18.

5. Raia AA, Macedo ALV. "Peritonite". In Raia AA, Zerbini EJ (eds). Clínica Cirúrgica Alípio Corrêa Netto - 4a edição. vol 4. São Paulo. Sarvier Editora de Livros Médicos, 1988, pp.27-42.

6. Hau T. Biology and treatment of peritonitis: the historic development of current concepts. J Am Coll Surg, 1998, 186: 475-484.

7. Oguz M, Bektemir M, Dulger M et al. Treatment of experimental peritonitis with intraperitoneal povidone-iodine solution. Can J Surg, 1988, 31: 169-171.

8. Torres OJM, Macedo EL, Melo TCM et al. Peritonite fecal em ratos: eficácia da lavagem da cavidade peritoneal com solução de cloreto de sódio a $0,9 \%$. Acta Cir Bras, 1999, 14: 65-68.

9. Uriarte AC, Lasheras PI, Martin JLM et al. Effect of povidone iodine and chlorhexidine on the mortality and bacterial clearance in the abdominal cavity of peritonitis rats. Eur J Surg, 1991, 157: 393-395.

10. Araujo ID. "Infecção cirúrgica pós-operatória". In Petroianu A (ed) - Lições de Cirurgia. $1^{\mathrm{a}}$ edição. Rio de Janeiro. Interlivros, 1997, pp 77-100.

11. Luke M, Iversen J, Sondergaard J. Ceftriaxone/metronidazole is more effective than ampicillin/netilmicin/metronidazole in the treatment of bacterial peritonitis. Eur J Surg, 1991, 157: 397-401.

12. Schein M, Gecelter G, Freinkel W. Peritoneal lavage in abdominal sepsis. Arch Surg, 1990, 125: 1132-1135.
13. Schein M, Saadia R, Decker G. Intraoperative peritoneal lavage. Surg Gynecol Obstet, 1988, 166:187-195.

14. Bartlett JG, Onderdonk AB, Louie T et al. Lessons from an animal model of intra-abdominal sepsis. Arch Surg, 1978, 113: 853-857.

15. Sayek I. Animal models for intra-abdominal infection. Hepatogastroenterology, 1997, 44: 923-926.

16. Bondar VM, Rago C, Cottone FJ et al. Chlorhexidine lavage in the treatment of experimental intra abdominal infection. Arch Surg, 2000, 135: 309-314.

17. Freire ANM, Kobata KM, Toledo MRF et al. Infecção peritoneal experimental em ratos. Acta Cir Bras, 1989, 4 (Suppl): 19-20.

18. Hau T, Nishikawa R. Irrigation of the peritoneal cavity and local antibiotics in the treatment of peritonitis. Surg Gynecol Obstet, 1983, 156: 25-30.

19. Hau T, Simmons RL. Animal models of peritonitis. Surg Gynecol Obstet, 1977, 144: 755-756.

20. Hovnanian AP, Saddawi N. An experimental study of consequences of intraperitoneal irrigation. Surg Gynecol Obstet, 1972, 134: 575-578.

21. Nichols RL, Smith JW et al. Peritonitis and intraabdominal abscess: an experimental model for the evaluation of human disease. J Surg Res, 1978, 25: 129-134.

22. Lineaweaver W, Howard R, Soucy D et al. Topical Antimicrobial Toxicity. Arch Surg, 1985, 120: 267-270.

23. Mathews EL, Adams MB, Condon RE. Toxicity of povidone-iodine peritoneal lavage in fecal peritonitis. Surg Forum, 1985, 36: 157-159.

24. Melo JRC. "Curativos". In: Fonseca FP, Savassi-Rocha PR (eds) - Cirurgia Ambulatorial. $3^{\text {a }}$ edição. Rio de Janeiro. Guanabara Koogan, 1999, pp.90-108.

25. Leão CEG. "Queimaduras". In: Fonseca FP, Savassi-Rocha PR, Cirurgia Ambulatorial. $3^{\text {a }}$ edição. Rio de Janeiro. Guanabara Koogan, 1999, pp.122-128.

26. Rambo WM. Irrigation of the peritoneal cavity with cephalotin. Am J Surg, 1972, 123: 192-195.

27. Gnocchi CA. Intra-abdominal infection and new quinolones. Medicina (Buenos Aires), 1999, 59 Suppl 1: 47-54. 
28. Gorbach SL. Treatment of intra-abdominal infections. J Antimicrob Chemother, 1993, 31 Suppl A: 67-78.

29. Nichols RL. Intra-abdominal sepsis. Clin Ther, 1987, 10 Suppl A: 50-58.

30. Rodrigues MAG, Lima AS. "Pré, per e pós-operatório". In Fonseca FP, Savassi-Rocha PR (ed) - Cirurgia Ambulatorial. $3^{\text {a }}$ edição. Rio de Janeiro. Guanabara Koogan, 1999, pp.5-13.

31. D’Ávila DO, Figueiredo AE. "Métodos de depuração extrarenal: hemodiálise, diálise peritoneal e novas técnicas" In Riella MC. Princípios de nefrologia e distúrbios hidroeletrolíticos. $1^{\mathrm{a}}$ edição. Rio de Janeiro. Guanabara Koogan, 1996, pp.607-645.

32. Sitting KM, Rohr MS, McDonald JC. "Parede abdominal, umbigo, mesentérios, omento e retroperitônio". In Sabiston DC (ed) - Tratado de Cirurgia. 14 a edição. vol 1. Rio de Janeiro. Guanabara Koogan, 1993, pp.683-695.
33. Cooper JE. Ethics and laboratory animals. Vet Rec, 1985,116: 594-595.

34. Petroianu A. "Pesquisa experimental". In Petroianu A (ed) - Ética, Moral e Deontologia Médicas. Rio de Janeiro. Guanabara Koogan, 2000, pp. 185-190.

Endereço para correspondência:

Dr. Andy Petroianu.

Av. Afonso Pena, 1626/1901.

30130-005 - Belo Horizonte-MG

E-mail: petroian@medicina.ufmg.br 